\title{
Proliferative and Glycolytic Assessment of the Whole-Body Bone Marrow Compartment
}

\author{
Tüm Vücut Kemik Iliği Kompartmanının Proliferatif ve Glikolitik Değerlendirilmesi
}

\author{
Mohammed Goryawala1, Malek Adjoua2, Seza Güleç3 \\ IMiami University Faculty of Medicine, Department of Radiology, Miami, USA \\ 2Florida International University Faculty of Medicine, Department of Electrical and Computer Engineering, Miami, USA \\ 3Florida International University Herbert Wertheim College, Department of Surgery, Miami, USA
}

\begin{abstract}
Objective: Quantitative assessment of active bone marrow (BM) in vivo is yet to be well-defined. This study aims to compare total body BM volume estimations obtained from use of both ${ }^{18} \mathrm{~F}-\mathrm{FLT}$ PET/CT and 18F-FDG PET/CT in order to consolidate higher cellular proliferation rates with imaging the highly active red BM in pancreatic cancer.

Methods: This phase I pilot study includes seven patients with pancreatic cancers who underwent both 18F-FLT and 18 F-FDG imaging each acquired within a week's duration. A CT-based classifier is used for segmenting bone into cortical and trabecular regions. The total BM volume is determined through statistical thresholding on PET activity found within the trabecular bone. Results: Results showed that $18 \mathrm{~F}-\mathrm{FLT}$ measures of red BM volume (RBV) were higher than those obtained from $18 \mathrm{~F}-\mathrm{FDG}$ $(\Delta=89.21 \mathrm{ml})$. RBV obtained using $18 \mathrm{~F}-\mathrm{FLT}$ in males were found to have high correlation with measured weight $\left(\mathrm{R}^{2}=0.61\right)$ and $\mathrm{BMI}\left(\mathrm{R}^{2}=0.70\right)$. The red BM fraction obtained from $18 \mathrm{~F}-\mathrm{FLT}$ was significantly different between males and females, with females showing much higher red bone matter within the trabecular bone $(p<0.05)$. In contrast to 18F-FLT, 18F-FDG BM measurements showed that RBV was significantly different between males and females $(p<0.05)$. Results also show that spinal activity SUV threshold for red BM segmentation is significantly different between 18F-FLT PET and 18F-FDG PET ( $p<0.05$ ). Conclusion: By combining 18F-FLT-PET and 18F-FDG-PET, this study provides useful insights for in vivo BM estimation through its proliferative and glycolytic activities.
\end{abstract}

Key words: PET/CT, 18F-FLT, $18 \mathrm{~F}-\mathrm{FDG}$, bone marrow imaging, image processing

Conflicts of Interest: The authors reported no conflict of interest related to this article.

\section{Özet}

Amaç: In vivo aktif Kemik iliği'nin (Ki) kantitatif değerlendirmesi tam olarak tanımlanmış değildir. Bu çalışmadaki amaç 18F-FLT ve 18 F FDG görüntüleme yöntemleriyle kemik iliğinin hücresel bölünme aktivitesi ile glikolitik aktivite ile tanımlanan hacimlerinin mukayesesini yapmaktır. Bu spesifik çalışmaya esas olan ana çalışma, pancreas kanserli hastalarda başlatılmış bir faz 1 araştırmasıdır.

Yöntem: By faz 1 çalışmaya pancreas kanseri olan yedi hasta dahil edilmiştir, bir hafta içerisinde hem 18F-FLT hem $18 \mathrm{~F}$-FDG görüntülemesi yapılmış, kemik dokusunu kortikal ve trabeküler bölgelere ayırmak için BT bazlı bir sınıflama kullanılmıştır. Total Ki hacmi, trabeküler kemikteki PET aktivitesinin istatiki bir eşikleme metodu uygulanarak belirlenmiştir.

Bulgular: $\left.{ }^{18 F-F L T ~ i l e ~ e l d e ~ e d i l e n ~ k ı r m ı z ı ~ K i ~ h a c m i ~(K K i) ~}{ }^{18 F-F D G ~ i l e ~ s a p t a n a d a n ~ d a h a ~ y u ̈ k s e k ~ b u l u n m u s ̧ t u r ~(~} \Delta=89,21 \mathrm{ml}\right) .{ }^{18} \mathrm{~F}-\mathrm{FLT}$ ile saptanan KKi erkeklerde ağırlık $\left(R^{2}=0,61\right)$ ve $K K I\left(R^{2}=0,70\right)$ ile yüksek korelasyon göstermektedir. ${ }^{18 F-F L T ~ i l e ~ e l d e ~ e d i l e n ~}$ kırmızı Ki fraksiyonu erkekler ve kadınlar arasında anlamlı farklılık göstermekteydi, kadınlarda trabeküler kemik içerisinde daha yüksek kırmızı kemik maddesi bulunmaktaydı $(p<0,05)$. 18F-FLT'nin aksine 18F-FDG Ki ölçümleri KKi'nin kadınlar ve erkekler

Address for Correspondence: Seza Güleç MD, Florida International University Herbert Wertheim College, Department of Surgery, Miami, USA Phone: +17866930821 E-mail: sgulec@fiu.edu Received: 24.01.2015 Accepted: 07.04.2015 
arsında anlamlı farkllık gösterdiği saptandı $(\mathrm{p}<0,05)$. Sonuçlar kırmızı Ki segmentasyonu için spinal aktivite SUV eşiğinin $18 \mathrm{~F}-\mathrm{FLT}$ PET ile 18F-FDG PET arasında anlamlı derecede farklı olduğunu gösterdi $(p<0,05)$.

Sonuç: Bu çalışma 18 F-FLT-PET ile 18F-FDG-PET'in birleştirilmesinin proliferative ve glikolitik aktivitelerine bağlı olarak in vivo Ki tahminine önemli katkı sağladığını göstermektedir.

Anahtar kelimeler: PET/CT, 18F-FLT, 18F-FDG, kemik iliği görüntülemesi, görüntüleme işlemi

Çıkar Çatışması: Yazarlar bu makale ile ilgili olarak herhangi bir çıkar çatışması bildirmemiştir.

\section{Introduction}

Bone Marrow (BM) is of vital importance in oncological applications since it is most sensitive to radiation and chemotherapy, and often regarded as the dose-limiting factor for systemic radionuclide therapies $(1,2,3)$. Moreover, estimating the volume of the highly active red BM is essential in stem cell transplantation studies (4), as timely stem cell support could improve patient recovery.

Furthermore, clinical studies, which aim to determine the correlation between administered dose and sensitivity to BM toxicity, can be confounded by potential effects of previous treatments.

Despite the advances in the current BM evaluation techniques, biopsy remains the gold standard for clinical diagnosis of functional and morphologic status $(5,6,7)$. However, biopsy that is dependent on site-specific sampling often fails to produce a correct estimation of the whole body BM distribution due to non- homogeneity within the skeletal system.

The International Commission on Radiological Protection (ICRP) estimates that total red marrow, which is the hematopoietically active tissue is $1.170 \mathrm{~g}$ in a healthy 40-year-old men and $900 \mathrm{~g}$ in women, and a total yellow marrow of about $2.480 \mathrm{~g}$ in men, and $1.800 \mathrm{~g}$ in women $(8,9)$. Systemic radionuclide therapies mostly affect the red $\mathrm{BM}$, and thus, it is of critical importance to estimate its volume in individuals undergoing treatment. As estimates of BM vary between individuals, patient-specific estimation of hematopoietically active red BM would enable better characterization of the BM compartment and hence better individualized dosimetry $(10,11)$.

Magnetic Resonance Imaging (MRI) based techniques that are capable of estimating water and fat components of the bone may be able to estimate BM volumes $(12,13,14)$. However, the infrequent use and long acquisition times of whole-body MRI hamper their use for BM estimation applications. More recently, quantitative SPECT based techniques using specific radiopharmaceuticals have been developed, which target the reticuloendothelial system as well as erythropoietic or granulopoietic cells for BM estimation $(10,15,16)$. These techniques suffer from the limitation due to tracer kinetics and the physics of single photon detection in SPECT. Recently, a study by Sambuceti et al. estimated the BM volume using 2-deoxy-2-(18F)-fluoro-D-glucose (18F-FDG)
PET/CT. The study that was based on a large population is the first of its kind in estimating intraosseous volume (IBV) by using SUV measures obtained from glucose uptake (17). Since glucose consumption in the IBV is indirectly correlated to the glycolytic activity of the BM, the distribution of the FDG PET/CT activity serves as a potent marker for estimating the red marrow within the skeleton.

Prior to $18 \mathrm{~F}-\mathrm{FLT}$, developed in the 1990s $(18,19)$, a number of markers have been used to predict the biologic behavior of tumors and outcome following surgical and medical treatments. At a basic histological level, mitotic index and lymphovascular invasion are commonly used to assess potentially aggressive tumors. Ki-67 is a nuclear antigen only present in the nuclei of proliferating cells, and good correlation between Ki-67 and S-phase indices have been reported by flow cytometry (20). Ki-67 immunohistochemistry $(\mathrm{IHC})$ has also been used to evaluate a tumors' proliferative activity.

Clinical evaluation and quantification of proliferative activity and tumor invasiveness can be performed by using FLT-positron emission tomography imaging. Similar to its mother drug azidothymidine, $18 \mathrm{~F}-\mathrm{FLT}$ acts as a terminator of the growing DNA chain. Actually, only a small amount of $18 \mathrm{~F}-\mathrm{FLT}$ is accumulated in DNA; rather, it is retained intracellularly after phosphorylation by thymidine kinase 1 . F-FLT pathway is similar to the imaging of glucose uptake pathway with 18F-FDG after trapping by hexokinase. Therefore, both compounds reflect accumulation by transport and subsequent activation by the first step in utilization pathways. $18 \mathrm{~F}-\mathrm{FLT}$ does not reflect the whole DNA synthesis, just as 18F-FDG does not reflect the whole glucose use. All clinical studies demonstrate a distinct BM uptake on $18 \mathrm{~F}$-FLT images. Although the exact mechanism is still being discussed, red marrow's precursor cell population with high proliferative activity is considered as the main reason for $18 \mathrm{~F}$-FLT localization.

The primary aim of this study is to estimate the distribution of hematopoietic cellular red BM and nonhematopoietic fibroareolar fatty yellow BM based on a combination of $18 \mathrm{~F}-\mathrm{FLT}$ PET and 18F-FDG PET, which both target BM compartment and evaluate the glycolytic and proliferative properties of BM cells, respectively. In this pilot study, a novel technique is proposed to estimate patient specific BM volumes based on whole body 18F-FLT PET and 18F-FDG PET. The whole bone compartment is first separated into cortical bone and trabecular bone by using 
Computed Tomography (CT). The study assumes that the $\mathrm{BM}$ resides within the trabecular compartment of the bone and uses statistical thresholds on PET images to estimate the total BM volume within the skeleton. Figure 1 depicts the general structure of BM estimation method.

\section{Materials and Methods}

\section{A. Patient Population and Imaging Protocol}

This investigation was performed on patients who underwent 18F-FLT to determine the key imaging characteristics of patients with pancreatic cancer. Eligibility criteria included age $\geq 18$, ability and willingness to give a written consent, life expectancy $>3$ months, and Karnofsky performance status $\geq 70$. Patient demographics for the studied population are presented in Table 1 .

The patient population did not show presence of visible bone metastases on either FDG or FLT PET/CT imaging. In addition, Complete Blood Cell (CBC) counts of the subjects reported an average glucose level of $117.85 \mathrm{mg} / \mathrm{dL}$, a mean RBC count of $4.54 \times 109$ cells $/ \mathrm{ml}$ and a mean platelet count of $385.85 \times 109$ per $\mathrm{ml}$. The results of the CBC tests along with absence of any bone metastases rendered the population a viable choice for the study of on BM compartment.

The study was performed under an FDA approved Investigational New Drug (IND) and after IRB review and approval. In this study, 3'-18F-fluoro-3'-deoxy-L- thymidine

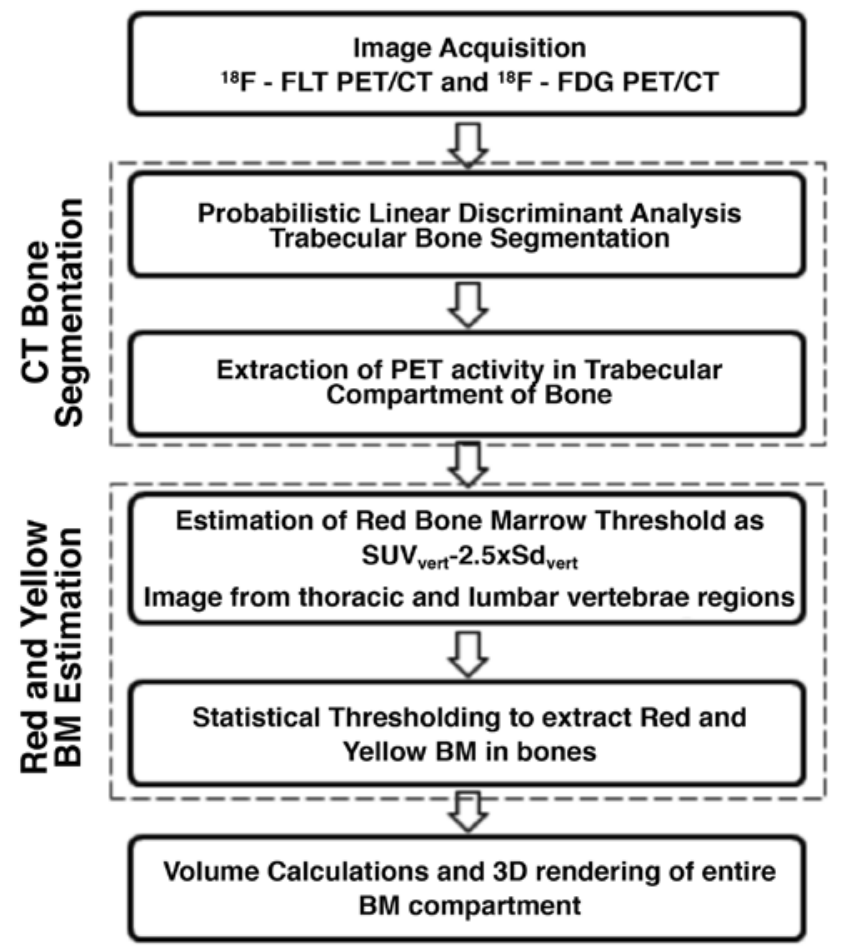

Figure 1. General structure of the entire BM estimation approach, showing the various steps of the algorithm for BM volume estimation was obtained from Cardinal Health 414, LLC. 18F- FLT administered activity was $10 \pm 1 \mathrm{mCi}$, and imaging time point was $60 \pm 15$ minutes post injection, whereas $18 \mathrm{~F}$ FDG was administered with an activity of $10 \pm 1 \mathrm{mCi}$, and imaging time point was $60 \pm 15$ minutes post injection. Images were obtained with 16-slice Siemens PET/CT. The scanning parameters for CT imaging were $140 \mathrm{kVp}, 80 \mathrm{~mA}$, 0.5 s rotation time, and $512 \times 512$-pixel matrix.

\section{B. Probabilistic LD A for Cortical and Trabecular Bone Segmentation}

Linear discriminant analysis (LDA) is a widely used technique in pattern recognition, statistics and machine learning to determine characteristic features that can aid in difficult segmentation tasks $(21,22,23,24,25)$. The technique, as used in this study, exploits the fact that Hounsfield values are different in cortical and trabecular bone on CT images (26). This difference in Hounsfield value can be used to train an LDA-based classifier for separating the entire bone into cortical and trabecular compartments.

The proposed LDA classifier estimates a posterior probability for each voxel of bone compartment on CT images (Figure 2A), for segmentation of bone into either cortical or trabecular compartments. In order to train the classifier, 1000 voxels of CT skeleton in seven patients are randomly chosen and manually assigned into one of the two groups: Cortical (C) or Trabecular (T).

The training phase estimates the parameters of linear discriminant functions for the two classes as given in Equation 1.

$d C L x, y, z=\alpha C+\beta C H V x, y, z$, and

$d T L x, y, z=\alpha T+\beta T H V(x, y, z)(1)$.

$\alpha C, \beta C, \alpha T, \beta T$ are the LDA parameters for the two groups cortical $(C)$ and $V(x, y, z)$ represents the Hounsfield value of a particular voxel of the CT image. The pprior $=0.5$, suggesting that a given voxel of the skeleton has an equal probability of belonging to either one of the two classes.

The segmentation of the entire bone into cortical and trabecular requires each $\mathrm{pC}$ or $\mathrm{pT}$ based on the linear score LC and LT, respectively. The posterior probabilities signify the likelihood of a voxel to belong to either of the groups. The linear scores LC and LT are estimated based on the Hounsfield value of the voxel under investigation as given by Equation 2 .

$L C(x, y, z)=d C L x, y, z+\log$ (pprior), and

$L T x, y, z=d T L x, y, z+\log$ (pprior) (2).

The technique computes two 3D posterior probability maps for every voxel of the skeleton. A higher posterior probability determines the grouping of the voxel.

Following this probabilistic segmentation of the skeleton into cortical and trabecular regions, a 3D connected islanding algorithm is employed to remove any spurious points marked erroneously as trabecular bone. The algorithm removes all connected components of the trabecular bone that have fewer than P voxels. The study uses a 26-point neighborhood connectedness for complete 
3D connectivity of every voxel that touches the faces, edges, or corners of the voxel under consideration.

The estimation of the trabecular and cortical bone regions is carried out for each patient by CTs co-registered to both the $18 \mathrm{~F}-\mathrm{FLT}$ and $18 \mathrm{~F}-\mathrm{FDG}$ PETs. Figure 2B,C shows the extracted cortical and trabecular regions of bone by using the posterior probability masks generated with Equation 2.

\section{Statistical BM Segmentation}

Estimation of hematopoietically active BM is based on the assumption that BM is located in the trabecular compartment of bone, and 18F-FLT voxel intensities, as seen on PET images, are correlated with the proliferative/ glycolytic activity of the BM. This estimation technique

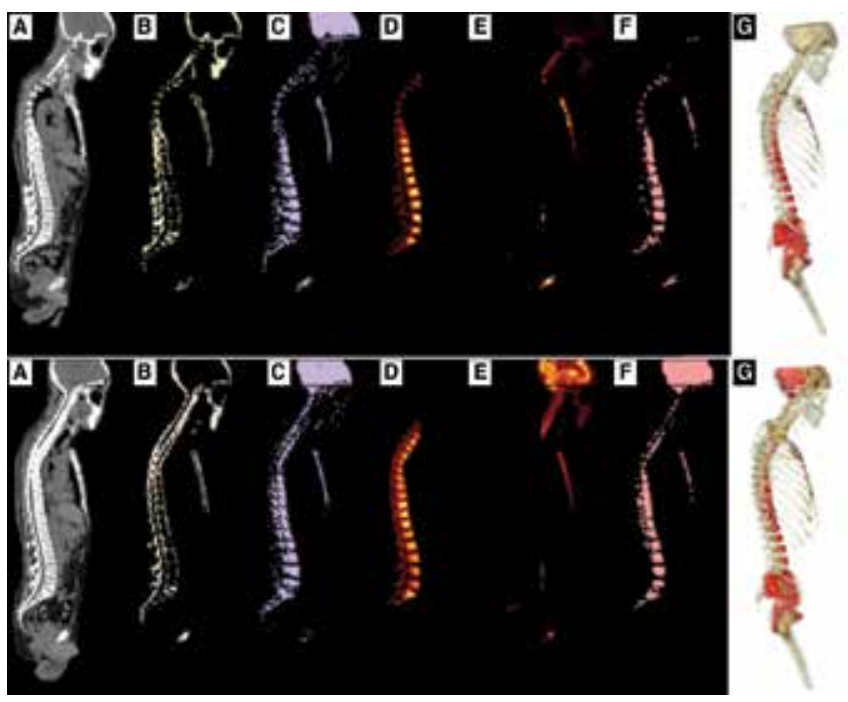

Figure 2. Full body images at various steps of the BM extraction process with the top row showing $18 \mathrm{~F}-\mathrm{FLT}$ and bottom row showing ${ }^{18} \mathrm{~F}-\mathrm{FDG}$ results. (A) CT image (B) Extracted cortical bone using probabilistic LDA (C) Extracted trabecular bone following probabilistic LDA (D) Activity in trabecular bone in thoracic and lumbar vertebrae regions (E) Activity in trabecular bone in the rest of the body excluding thoracic and lumbar vertebrae regions (F) Thresholded BM map generated after applying a statistical thresholding on PET image. (G) 3D rendering of BM in the entire body, with red regions showing red $\mathrm{BM}$ and yellow regions corresponding to yellow BM. The cortical bone overlay is showing using a transparent white overlay extracts only the FLT/FDG activity located in the trabecular bone by using the CT-based 3D posterior probability maps obtained in the preceding step. Figure $2 \mathrm{E}$ shows the resultant image obtained by masking the registered FLT-PET images with the posterior probability map of the trabecular tissue.

Thresholding in PET images has always been a topic of great interest, with thresholds playing a critical role in determining the correct volume/area of the extracted object (27). Various studies with 18F-FLT have shown different Standard Uptake Value (SUV) thresholds deemed optimal for determining the functionally active $\operatorname{BM}(28,29)$. In addition, studies have shown that the SUV threshold varies for different bones of the body, therefore, no one single SUV threshold could possibly be considered as the gold standard (28).

To overcome the contentious issue of thresholds, a completely statistically driven approach outlined by Sambuceti et al. (17) has been adopted for both 18F-FLT and 18F-FDG based BM estimation. The approach initially estimates the mean (SUV) and standard deviation (SD vert) of all the activity located within the trabecular bone, in the thoracic and lumbar vertebrae regions as shown in Figure 2 (D). The technique estimates the red (active) BM volume by accounting all voxels of the trabecular bone that are above the threshold computed as $S_{U} V_{\text {vert }}-2.5 \times S D_{\text {vert }}$. A unique property for estimating the red $\mathrm{BM}$ in this study is in the use of patient-specific thresholds rather than a fixed threshold to account for differences in uptake across patients. Less-active yellow BM is estimated as the fraction of the trabecular bone volume below the red BM threshold. Figure $2 \mathrm{~F}$ illustrates the resultant image after the thresholding operation showing the statistically significant voxels of the BM.

\section{Volume Estimation}

Cost-effective third party software called ScanIPTM developed by Simpleware Ltd. based in the United Kingdom is utilized for estimating the volume of the statistically significant BM. The calculated volumes are in milliliters $(\mathrm{ml})$. Figure $2 \mathrm{G}$ shows $3 \mathrm{D}$ rendering of $\mathrm{BM}$ in the entire body with red regions showing red $\mathrm{BM}$ and yellow regions

\section{Table 1. Patient Demographics}

\begin{tabular}{|c|c|c|c|c|c|c|}
\hline Subject & $\begin{array}{l}\text { Measured } \\
\text { Weight (kg) }\end{array}$ & Height (cm) & Gender & $\begin{array}{l}\text { Age at time of } \\
\text { Imaging (years) }\end{array}$ & $\begin{array}{l}\text { Ideal Body Weight } \\
\text { (kg) }\end{array}$ & $\begin{array}{l}\text { Body Mass Index } \\
\text { (BMI) }\left(\mathrm{kg} / \mathrm{m}^{2}\right)\end{array}$ \\
\hline 1 & 61.68 & 157 & $F$ & 65 & 52.38 & 24.87 \\
\hline 2 & 138.79 & 180 & $M$ & 54 & 72.89 & 42.68 \\
\hline 3 & 104.32 & 185 & M & 53 & 76.70 & 30.34 \\
\hline 4 & 68.49 & 180 & M & 59 & 72.89 & 21.06 \\
\hline 5 & 63.04 & 165 & M & 68 & 61.50 & 23.13 \\
\hline 6 & 68.94 & 183 & M & 63 & 74.79 & 20.61 \\
\hline 7 & 70.76 & 160 & $\mathrm{~F}$ & 59 & 54.11 & 27.66 \\
\hline Average & $82.29 \pm 28.79$ & $172.85 \pm 11.76$ & & $60.14 \pm 5.55$ & $146.54 \pm 2.62$ & $27.19 \pm 7.66$ \\
\hline
\end{tabular}


showing corresponding yellow BM. The cortical bone is shown using a transparent white overlay.

\section{E. Statistical Analysis}

All results are presented in the form of mean \pm standard deviation. Linear regressions as performed in this study make use of the least square technique and report the $\mathrm{R}^{2}$ of the fit and the p-value. All comparative results between 18F-FLT and 18F-FDG based estimations are carried out through paired t-tests. A p-value of $<0.05$ is considered statistically significant.

\section{F. Ethics Statement}

The research has been approved by the Western Institutional Review Board. A Certificate of approval from the WIRB has been obtained. Each participant provided a written consent to participate in the study as per the requirements and guidelines of the IRB.

\section{Results}

\section{G. Probabilistic LD A Segmentation}

To assess the results of the Probabilistic LDA used for segmenting the bone into cortical and trabecular regions, the leave-one-out cross-validation (LOOCV), which is a trusted model for assessing the performance of classifiers, is used in this study. The classification experiment was implemented 50 times on 50 random training sets of 1000 samples. Table 2 provides the average training and LOOCV testing metrics (accuracy, sensitivity, specificity and precision) of the classification results performed across all the 14 CT scans (seven co-registered to $18 \mathrm{~F}-\mathrm{FLT}$ and seven co-registered to $18 \mathrm{~F}-\mathrm{FDG}$ ).

\section{H. Whole Body BM Volumetric Assessment}

Estimated BM volumes for the study patients are illustrated in Tables 3 and 4 using 18F-FLT and 18F-FDG,

Table 2. Classification performance

\begin{tabular}{lllll}
\hline & Accuracy & Sensitivity & Specificity & Precision \\
\hline Training & $0.94 \pm 0.04$ & $0.96 \pm 0.02$ & $0.91 \pm 0.04$ & $0.92 \pm 0.05$ \\
LOOCV & $0.92 \pm 0.04$ & $0.93 \pm 0.03$ & $0.90 \pm 0.07$ & $0.91 \pm 0.04$
\end{tabular}

respectively, showing the average red and yellow BM volumes for each patient with the standard deviation obtained upon executing the algorithm 50 times. The tables also provide the volumes of the trabecular bone region along with the fraction of red BM within the trabecular region.

In addition, it is seen that the estimates of Trabecular Bone Volume (IBV) from the CT images co-registered to either FLT or FDG PET/CT were not significantly different $(p=0.49)$. Additionally, it is seen that 18F-FLT based measures of red BM volume (RBV) were higher than those obtained by 18 F-FDG $(\Delta=89.21 \mathrm{ml})$, but results of a paired t-test demonstrate that they were not significantly different $(p=0.55)$. Consecutively, estimated total body yellow BM volume (YBV) from the two different tracers namely $18 \mathrm{~F}-\mathrm{FLT}$ and 18F-FDG were not significantly different $(p=0.112$ ). The red BM fraction estimated from 18F-FLT was higher

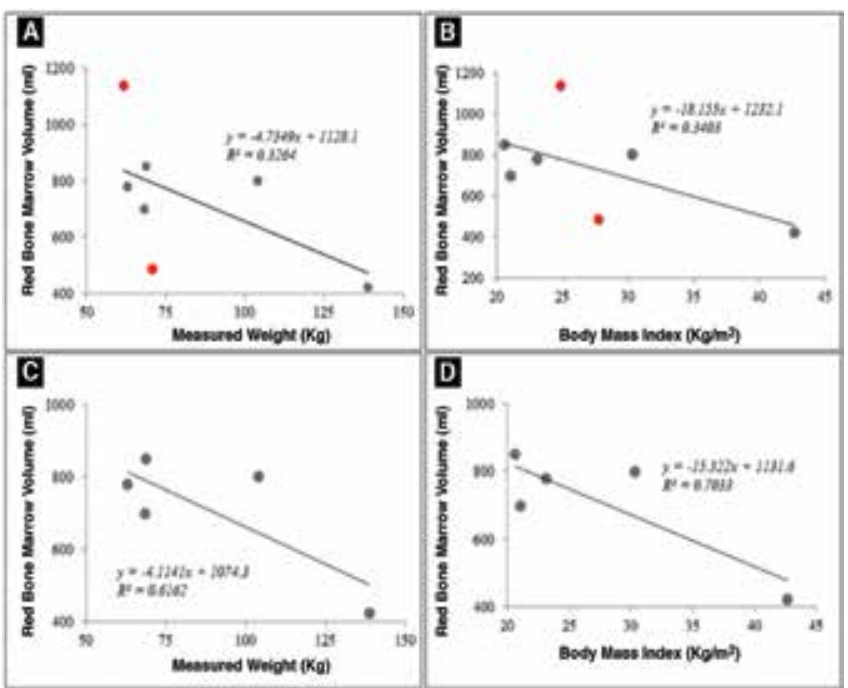

Figure 3. Influence of (A) Measured Body Weight, and (B) Body Mass Index (BMI) on Red BM Volume (RBV) obtained from ${ }^{18} \mathrm{~F}-\mathrm{FLT}$ imaging in all subjects, whereas (C) and (D) show the influence of measured body weight and $\mathrm{BMI}$ in only males, respectively. The RBVs showed better correlation to physical measurements when female subjects were excluded

Table 3. Estimated Whole Body BM volumes using 18F-FLT PET/CT imaging

\begin{tabular}{llllll}
\hline Patient & Gender & Red (RBV) & Yellow (YBV) & Trabecular Bone Volume (IBV) & $\begin{array}{l}\text { Red BM Fraction } \\
\mathbf{8 8} \text { (RBV/IBV) }\end{array}$ \\
\hline 1 & $\mathrm{~F}$ & $1136.37 \pm 17.7$ & $513.63 \pm 22.87$ & $1650 \pm 22.67$ & 0.69 \\
2 & $\mathrm{M}$ & $421.16 \pm 26.94$ & $598.84 \pm 16.11$ & $1020 \pm 23.27$ & 0.41 \\
3 & $\mathrm{M}$ & $799.73 \pm 12.61$ & $820.27 \pm 18.8$ & $1620 \pm 16.21$ & 0.49 \\
4 & $\mathrm{M}$ & $697.94 \pm 33.64$ & $682.06 \pm 22.7$ & $1380 \pm 28.44$ & 0.51 \\
5 & $\mathrm{M}$ & $778.07 \pm 28.53$ & $551.93 \pm 18.83$ & $1330 \pm 24.76$ & 0.59 \\
6 & $\mathrm{M}$ & $849.31 \pm 21.7$ & $640.69 \pm 11.64$ & $1490 \pm 19.54$ & 0.57 \\
7 & $\mathrm{~F}$ & $486.52 \pm 29.63$ & $143.48 \pm 23.35$ & $630 \pm 25.67$ & 0.77 \\
Average & & $738.44 \pm 220.95$ & $564.42 \pm 195.19$ & $1302.86 \pm 337.12$ & $0.58 \pm 0.11$
\end{tabular}


than that estimated from 18F-FDG but was not statistically different for the 7 patients in the study. $(\Delta=0.08 ; p=0.25)$.

I. Effects of Weight, Height, and BMI on Whole Body BM Volumes

For $18 \mathrm{~F}-\mathrm{FLT}$ based BM measurements it is seen that although the RBV was not affected by gender $(p=0.653)$, the YBV was significantly different between males and the females $(p<0.05)$. Also, the RBV did not show a good correlation with the measured weight $\left(R^{2}=0.32\right.$; Figure $\left.3 A\right)$,
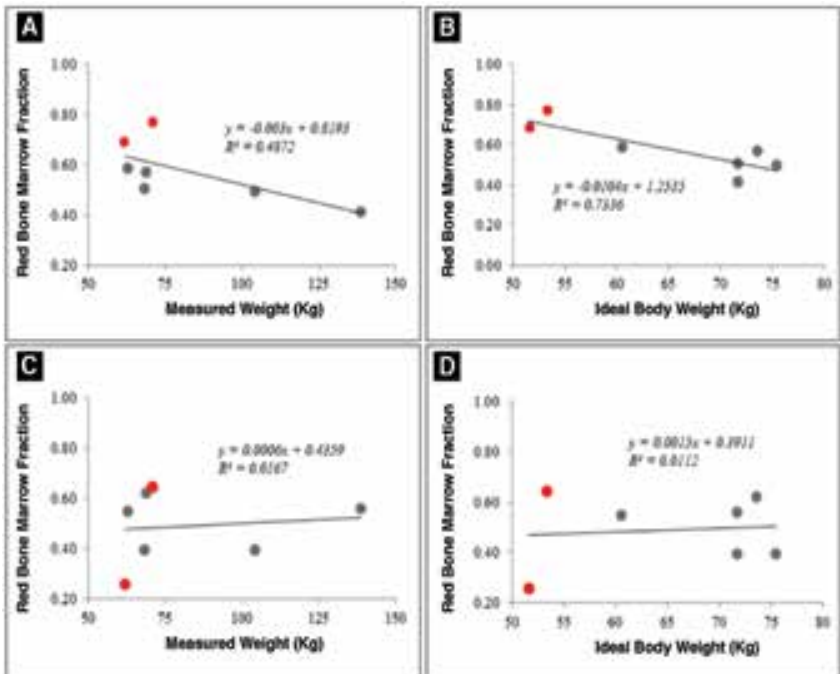

Figure 4. Correlation between Red BM Fraction and (A) Measured Weight and (B) Ideal Body Weight using ${ }^{18}$ F-FLT PET imaging. Parts (C) and (D) show the same correlation on $18 \mathrm{~F}$-FDG PET. A higher correlation was detected between RBV and measured weight and ideal body weight in ${ }^{18} \mathrm{~F}-\mathrm{FLT}$ based RBV estimations as compared to ${ }^{18} \mathrm{~F}-\mathrm{FDG}$ imaging

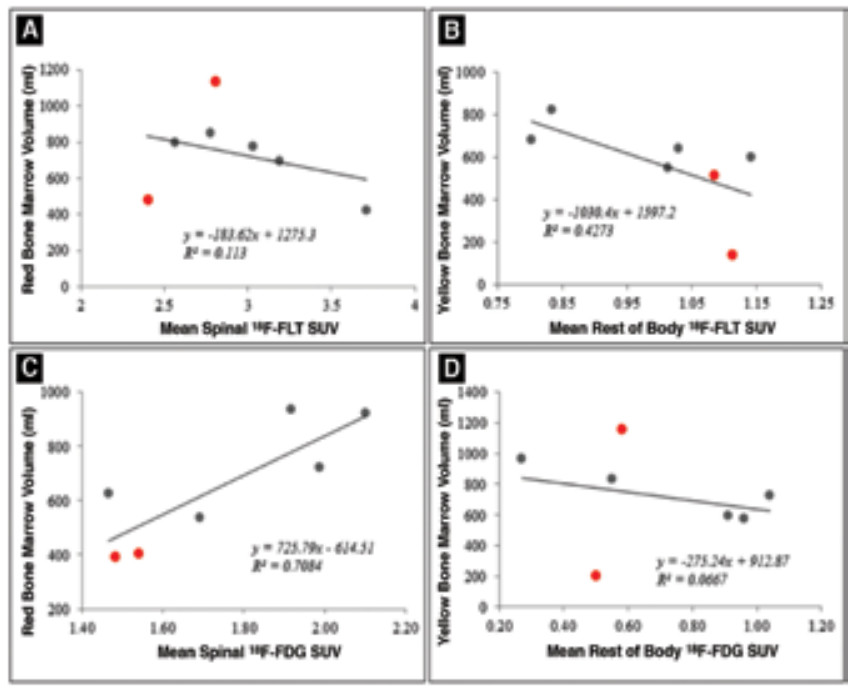

Figure 5. Correlation between (A) Red BM Volume (RBV) to mean spinal SUV and (B) Yellow BM Volume (YBV) to mean rest of body SUV for ${ }^{18 F-F L T ~}$ imaging. Parts (C) and (D) show the same result for ${ }^{18} \mathrm{~F}-\mathrm{FDG}$ imaging. RBV are well-correlated for ${ }^{18 F-F D G ~ b u t ~ n o t ~ f o r ~}{ }^{18 F-F L T ~ i m a g i n g ~}$ measured height $\left(R^{2}=0.06\right)$, Body Mass Index $(R 2=0.34$; Figure $3 \mathrm{~B})$ and ideal body weight $\left(\mathrm{R}^{2}=0.05\right)$. Similar trends were seen for YBV and IBV for the subjects in this study. However, on the exclusion of female subjects $(n=2)$ from regression analysis, it is observed that a higher correlation was obtained for RBV with measured weight $\left(R^{2}=0.61\right.$; Figure $3 C)$ and the $B M I\left(R^{2}=0.70\right.$; Figure $\left.3 D\right)$.

Finally, the red BM fraction was found to be loosely correlated with the measured weight $\left(R^{2}=0.49\right.$; Figure $\left.4 A\right)$ and well correlated to the measured height $\left(R^{2}=0.68\right)$ and the ideal body weight ( $\mathrm{R}^{2}=0.73$; Figure $\left.4 \mathrm{~B}\right)$. It was also significantly different between males and females, with females showing much higher red bone matter within trabecular bone $(p<0.05)$.

For 18F-FDG based BM measurements, it was seen that RBV was significantly different between males and females $(p<0.05)$, however YBV and IBV were not statistically different between the two genders. Also for $18 \mathrm{~F}-\mathrm{FDG}$, RBV did not correlate well with measured weight $\left(R^{2}=0.24\right)$, and Body Mass Index $\left(R^{2}=0.08\right)$ and correlated weakly with measured height $\left(R^{2}=0.43\right)$ and ideal body weight $\left(R^{2}=0.47\right)$.

An interesting feature is seen among males in the study population, where stronger correlation of the IBV with measured weight $\left(R^{2}=0.77\right)$, and $B M I\left(R^{2}=0.61\right)$ were observed. Also, red BM fraction was not strongly correlated to any demographic features when measured using 18F-FDG PET/CT (Figure 4C and 4D).

\section{J. SUV Assessment}

The SUV measure of 18F-FLT images is an indicator of the proliferative activity of BM, whereas the SUV measure in 18F-FDG imaging is indicative of the glycolytic activity of the BM compartment. Table 5 shows the mean SUV values corresponding to the spinal column and the rest of the body (ROB). Results show that the spinal activity SUV that is used to determine the threshold for red BM segmentation was significantly different between 18F-FLT PET and 18F-FDG PET $(p<0.05)$. Also, the SUV for the rest of the body (excluding the skull) was found to be different between the two imaging tracers. Moreover, the results of an ANOVA for both FDG and FLT based BM estimation suggest that the mean spinal and rest-of-body SUVs were not different among males and females.

In addition, as seen in Figure 5, red BM volumes were not very well correlated to the mean spinal SUVs for $18 \mathrm{~F}-\mathrm{FLT}$ $\left(R^{2}=0.13\right.$; Figure $\left.5 A\right)$, but were comparatively better correlated in the case of $18 \mathrm{~F}-\mathrm{FDG}\left(\mathrm{R}^{2}=0.71\right.$; Figure $\left.5 \mathrm{C}\right)$. Also, the yellow BM volumes were not very well correlated with the mean SUVs of the rest of the body for both FLTand FDG-based estimations (Figure 5B and 5D).

An important finding is that the SUV values in the spine and rest of the body vary significantly for different subjects. This variation is an important aspect that needs to be considered when 18F-FLT images are thresholded using fixed SUV values. This variation in the different statistically 
meaningful SUV thresholds combined with the fact that the mean SUV value in the trabecular bone varies significantly from patient to patient, suggests that the use of statistical thresholds, like the one suggested in this article, may be advantageous for obtaining more meaningful results.

\section{Discussion}

To the best of our knowledge of the literature, this study is the first to compare total body BM volume estimations obtained from the use of 18F-FLT PET/CT and 18F-FDG $\mathrm{PET} / \mathrm{CT}$. The study presented an augmented approach for eliciting a better understanding of the BM compartment by combining the glycolytic activity of 18F-FDG PET and proliferative activity of $18 \mathrm{~F}-\mathrm{FLT}$ PET, each being acquired within a week's duration for the same patient. Other studies using 18F-FLT for imaging the BM compartment have focused on particular regions of interest rather than providing a measure of the total active BM in the human body $(28,30)$. Also, the nature of the proposed technique renders it possible to extract and quantify the active BM within any bone in the body.

An important contribution relates to the use of the probabilistic LDA technique for extracting compact and trabecular bone compartments. This probabilistic technique is based on the assumption that compact bone in CT images appears as having the highest Hounsfield value and that trabecular bone located in its cavity has a significantly lower Hounsfield value $(11,26)$. This assumption along with the probabilistic training approach enables the technique to be applied on every single slice of the $\mathrm{CT}$ image without any human intervention, once the classifier is trained.

Also, as seen in the results, the IBV estimations are not significantly different between those estimated from CTs co-registered to $18 \mathrm{~F}-\mathrm{FLT}$ and $18 \mathrm{~F}$-FDG PETs. This finding is expected in such studies since the discrepancies in measurements of the IBV can result in incorrect estimations of BM volumes. Also, since the imaging of FLT and FDG $\mathrm{PET} / \mathrm{CT}$ is not performed more than a week apart, no expected discrepancies should be observed in the CT-based bone volume measurements as seen in the results. The insignificant differences may be due to the probabilistic nature of the segmentation algorithm for delineating cortical from trabecular bone.

Moreover, the probabilistic LDA based technique classifies the brain as trabecular bone as can be seen in Figure 2C, but it is not a major source of error in BM estimation due to the targeted uptake of 18F-FLT. Brain tissue does not show significant uptake of $18 \mathrm{~F}$ - FLT, as in the case of FDG, which is the primary reason why the skull needs to be omitted from the quantification purposes. The use of $18 \mathrm{~F}-\mathrm{FLT}$ offers a unique opportunity to quantify the BM volume (albeit negligible) in the skull, which is not estimated in studies based on FDG. It is seen in this study that indeed negligible $\mathrm{BM}$ is found in the skull, which is conform to the proposed BM distribution, as was also confirmed in other studies

Table 4. Estimated Whole Body BM volumes using 18F-FDG PET/CT imaging

\begin{tabular}{llllll}
\hline \multicolumn{7}{c}{ Patient } & Gender & Red (RBV) & Yellow (YBV) & Trabecular Bone Volume (IBV) & Red BM Fraction (RBV/IBV) \\
\hline 1 & $\mathrm{~F}$ & $405.2 \pm 21.49$ & $1155 \pm 24.93$ & $1560.2 \pm 19.01$ & 0.25 \\
2 & $\mathrm{M}$ & $922.2 \pm 15.63$ & $728.3 \pm 18.22$ & $1650.5 \pm 21.63$ & 0.55 \\
3 & $\mathrm{M}$ & $625.6 \pm 17.97$ & $965 \pm 18.38$ & $1590.6 \pm 19.72$ & 0.39 \\
4 & $\mathrm{M}$ & $537.9 \pm 22.69$ & $833.1 \pm 26.1$ & $1371 \pm 16.45$ & 0.39 \\
5 & $\mathrm{M}$ & $723.4 \pm 19.76$ & $597 \pm 21.94$ & $1320.5 \pm 18.24$ & 0.54 \\
6 & $\mathrm{M}$ & $937 \pm 22.81$ & $573.1 \pm 21.53$ & $1510.1 \pm 21.72$ & 0.62 \\
7 & $\mathrm{~F}$ & $393.4 \pm 17.93$ & $214.6 \pm 18.94$ & $608 \pm 18.59$ & 0.64 \\
Average & & $649.23 \pm 207.30$ & $723.75 \pm 281.35$ & $1372.98 \pm 330.85$ & $0.49 \pm 0.13$
\end{tabular}

Table 5. SUV measures

\begin{tabular}{llllll}
\hline PET Tracer & & Overall & Male & Female & p-value (Male vs. Female) \\
\hline \multirow{2}{*}{ 18F-FDG } & Spinal & $1.74 \pm 0.26$ & $1.83 \pm 0.25$ & $1.51 \pm 0.04$ & 0.152 \\
& ROB & $0.69 \pm 0.29$ & $0.75 \pm 0.33$ & $0.54 \pm 0.06$ & 0.438 \\
& & & & & \\
18 F-FLT & Spinal & $2.92 \pm 0.44$ & $3.05 \pm 0.44$ & $2.56 \pm 0.29$ & 0.245 \\
& ROB & $1.00 \pm 0.13$ & $0.96 \pm 0.14$ & $1.09 \pm 0.02$ & 0.265 \\
p-value (FDG vs. FLT) & Spinal & $<0.05$ & & & \\
& ROB & $<0.05$ & & &
\end{tabular}


$(17,28)$. The quantitative measurement of the total active $\mathrm{BM}$ volume in the body has not been clearly defined in the literature. The primary description of the BM compartment and its related measures come from the 1926 study by Mechanik and its various reviews by Woodward and Holodny, Cristy and Ellis $(31,32,33,34)$.

Mechanik's study that is based on 13 subjects who died of non-hematological diseases is the fundamental study on which all BM estimates are based (33). A recent study by Sambuceti et al. estimated the BM volume using FDG PET/ CT. This study that was based on a large population was first of its kind to estimate intraosseous volume (IBV) using SUV measures obtained from glucose uptake (17).

This study showed that $18 \mathrm{~F}-\mathrm{FLT}$ based BM estimations were higher than those obtained from 18F-FDG PET imaging, all but for two patients. The differences between the BM estimations for the two imaging modalities may be a result of the difference in the distribution and mechanism of the PET tracer within the body.

18F-FLT enables us to visualize the true hematopoietically active BM compartment of the body in order to estimate the whole body volume. Additionally, the assessment of the RBV was very close to the one obtained by Sambuceti et al., which showed that the mean RBV was approximately $541 \pm 195 \mathrm{ml}$.

The measured BM volumes in this study are slightly lower than those reported from other studies, which are based on cadaver studies. There are various reasons that could account for such differences. The difference in values from the Mechanik data can be explained due to the different methods used. Mechanik employed prolonged boiling of the bone in a post-mortem analysis whereas the presented technique involves metabolic imaging.

This study also showed that the RBV volumes estimated by FLT were not significantly different between males and females as was the case using FDG. Other studies based on FDG have showed that assessments of BM were significantly different between the two genders as was confirmed here in this study (17). Also, we found that the mean SUVs of the spinal region and the rest of the body were significantly different between FLT- and FDG-based imaging. The higher mean SUV when using FLT signifies that FLT is a better targeting agent for BM estimation as compared to FDG. Also, the ratio of the mean spinal activity SUV to the mean SUV of the rest of body is higher in FLT imaging (2.92 vs. 2.52 for FDG), which may provide a higher contrast in estimating red $\mathrm{BM}$ and hence an improved estimation of RBV.

Although the proposed approach of this study is based on finding statistically meaningful BM volumes, it does have some intrinsic limitations. The primary limiting factor is the effect of partial volume averaging, which is observed both in CT and PET images (35). This may often lead to an overestimation of the cortical and trabecular regions and in turn the BM volumes. Also, motion artifacts due to the long imaging time of the PET as compared to CT is another potential source of estimation error (36). The probabilistic LDA technique has a cross-validated accuracy of $91 \%$, which may be attributed to errors in estimating the boundary between the cortical and trabecular bone regions, which in turn could lead to errors in BM volume measurements. Finally, the size of the population of this pilot study is a primary limitation and current findings are needed to be verified through the inclusion of more subjects as they become available, and as we continue to augment our understanding of pancreatic cancer in order to offer better and more effective means for diagnosis and ultimately better treatment. The small number of patients included in this pilot study is dictated primarily by the nature of the disease which observes the lack of simple early detection methods and the earliest indications of disease being nonspecific. Also, the intensive nature of the imaging task with both $18 \mathrm{~F}-\mathrm{FLT}$ and $18 \mathrm{~F}-\mathrm{FDG}$ PET/CT may have been a limiting factor for inclusion of subjects.

Although some limitations exist, the study provides a unique quantitative assessment of the whole-bone marrow compartment using its proliferative and glycolytic activity in the same patients to provide new insights in the distribution of the active bone marrow for various applications.

Concept: Seza Güleç

Design: Seza Güleç, Mohammed Goryawala

Data Collection or Processing: Mohammed Goryawala Analysis or Interpretation: Mohammed Goryawala, Malek Adjouadi, Seza Güleç

Literature Search: Mohammed Goryawala

Writing: Mohammed Goryawala, Malek Adjouadi, Seza Güleç

Peer-review: Externally peer-reviewed.

\section{References}

1. Gulec SA, Mesoloras G, Dezarn WA, McNeillie P, Kennedy AS. Safety and efficacy of Y-90 microsphere treatment in patients with primary and metastatic liver cancer: the tumor selectivity of the treatment as a function of tumor to liver flow ratio. J Transl Med 2007;5:15.

2. Gulec SA, Mesoloras G, Stabin M. Dosimetric techniques in 90Ymicrosphere therapy of liver cancer: The MIRD equations for dose calculations. J Nucl Med 2006:47:1209-1211.

3. Gulec SA, Siegel JA. Posttherapy radiation safety considerations in radiomicrosphere treatment with $90 \mathrm{Y}$-microspheres. I Nucl Med 2007;48:2080-2086.

4. Hindorf C, Glatting G, Chiesa C, Linden O, Flux G. EANM Dosimetry Committee guidelines for bone marrow and whole-body dosimetry. Eur J Nucl Med Mol Imaging 2010;37:1238-1250.

5. Knowles S, Hoffbrand AV. Procedures in Practice .1. Bone-Marrow Aspiration and Trephine Biopsy. Brit Med J 1980;281:204-205.

6. Knowles S, Hoffbrand AV. Bone-Marrow Aspiration and Trephine Biopsy .2. Brit Med J 1980;281:280-281.

7. Lawrence JB, Eleff $M$, Behm FG, Johnston CL. Bone-Marrow Examination in Small Cell-Carcinoma of the Lung - Comparison of Trephine Biopsy with Aspiration. Cancer 1984;53:2188-2190.

8. ICRP. Report of the task group on reference man: ICRP publication 23. Oxford Pergamon Press; 1975.

9. Basic anatomical and physiological data for use in radiological protection: reference values. A report of age- and gender-related differences in the anatomical and physiological characteristics of reference individuals. ICRP Publication 89. Ann ICRP 2002;32:5-265.

10. Agool A, Glaudemans AW, Boersma HH, Dierckx RA, Vellenga E, Slart RH. Radionuclide imaging of bone marrow disorders. Eur J Nucl Med Mol Imaging 2011;38:166-178. 
11. Blebea JS, Houseni $M$, Torigian DA, Fan C, Mavi A, Zhuge $Y$, Iwanaga T, Mishra S, Udupa J, Zhuang J, Gopal R, Alavi A. Structural and functional imaging of normal bone marrow and evaluation of its age-related changes. Semin Nucl Med 2007;37:185-194.

12. Bracken J, Nandurkar D, Radhakrishnan K, Ditchfield M. Normal paediatric bone marrow: Magnetic resonance imaging appearances from birth to 5 years. J Med Imaging Radiat Oncol 2013;57:283-291.

13. Silva Jr JR, Hayashi D, Yonenaga T, Fukuda K, Genant HK, Lin C, Rahmouni A, Guermazi A. MRI of bone marrow abnormalities in hematological malignancies. Diagn Interv Radiol 2013;19:393-399.

14. Vogler JB, 3rd, Murphy WA. Bone marrow imaging. Radiology 1988;168:679-693.

15. Datz FL, Taylor A. The Clinical Use of Radionuclide Bone-Marrow Imaging. Semin Nucl Med 1985:15:239-259.

16. Desai AG, Thakur ML. Radiopharmaceuticals for Spleen and BoneMarrow Studies. Semin Nucl Med 1985:15:229-238.

17. Sambuceti G, Brignone M, Marini C, Massollo M, Fiz F, Morbelli S, Buschiazzo A, Campi C, Piva R, Massone AM, Piana M, Frasson F. Estimating the whole bone-marrow asset in humans by a computational approach to integrated PET/CT imaging. Eur J Nuc Med Mol Imaging 2012;39:1326-1338.

18. Herrmann $K$, Ott $K$, Buck AK, Lordick F, Wilhelm D, Souvatzoglou M, Becker K, Schuster T, Wester HJ, Siewert JR, Schwaiger M, Krause BJ. Imaging gastric cancer with PET and the radiotracers F-18-FLT and F-18-FDG: A comparative analysis. J Nucl Med 2007:48:1945-1950.

19. Yue J, Chen L, Cabrera AR, Sun $X$, Zhao S, Zheng F, Han A, Zheng J, Teng X, Ma L, Ma Y, Han D, Zhao X, Mu D, Yu J, Li Y. Measuring tumor cell proliferation with 18F-FLT PET during radiotherapy of esophageal squamous cell carcinoma: a pilot clinical study. J Nucl Med 2010:51:528-534.

20. Chalkidou A, Landau DB, Odell EW, Cornelius VR, O'Doherty MJ, Marsden PK. Correlation between Ki-67 immunohistochemistry and 18F-fluorothymidine uptake in patients with cancer: A systematic review and meta-analysis. Eur J Cancer 2012;48:3499-3513.

21. Lachenbruch PA. Discriminant analysis. New York: Hafner Press; 1974.

22. Lobo A. Image segmentation and discriminant analysis for the identification of land cover units in ecology. IEEE Geoscience and Remote Sensing Society 1997;35:1136-1145.

23. McLachlan GJJW, Sons WI. Discriminant analysis and statistical pattern recognition. Hoboken NJ: Wiley-Interscience; 2004.
24. Tang $Y, M u ~ W$, Zhang $X$, Yang Y. Modified Fuzzy Linear Discriminant Analysis for Threshold Selection. Circuits Syst Signal Process 2013:32:711-726.

25. Goryawala M, Guillen MR, Cabrerizo M, Barreto A, Gulec S, Barot TC, Suthar RR, Bhatt RN, Mcgoron A, Adjouadi M. A 3-D liver segmentation method with parallel computing for selective internal radiation therapy. IEEE Trans Inf Technol Biomed 2012;16:62-69.

26. Buie HR, Campbell GM, Klinck RJ, MacNeil JA, Boyd SK. Automatic segmentation of cortical and trabecular compartments based on a dual threshold technique for in vivo micro-CT bone analysis. Bone 2007:41:505-515.

27. Bhatt R, Adjouadi M, Goryawala M, Gulec SA, McGoron AJ. An algorithm for PET tumor volume and activity quantification: without specifying camera's point spread function (PSF). Med Phys 2012;39:4187-202

28. Agool A, Schot BW, Jager PL, Vellenga E. 18F-FLT PET in hematologic disorders: a novel technique to analyze the bone marrow compartment. J Nucl Med 2006;47:1592-1598.

29. Thie JA. Understanding the standardized uptake value, its methods, and implications for usage. J Nucl Med 2004;45:1431-1434.

30. Koizumi M, Saga T, Inubushi M, Fukumura T, Yoshikawa K, Yamamoto N, Nakajima M, Sugane T, Baba M. Uptake Decrease of Proliferative PET Tracer (FLT)-F-18 in Bone Marrow after Carbon Ion Therapy in Lung Cancer. Mol Imaging Biol 2011;13:577-582.

31. Cristy M. Active Bone-Marrow Distribution as a Function of Age in Humans. Phys Med Biol 1981;26:389-400.

32. Ellis RE. The distribution of active bone marrow in the adult. Phys Med Biol 1961;5:255-258

33. Mechanik N. Untersuchungen ueber das Gewicht des knochenmark des Menschen. Z Gesamte Anat 1926:79:58-99.

34. Woodard HQ, Holodny E. A summary of the data of Mechanik on the distribution of human bone marrow. Phys Med Biol 1960;5:5759

35. Aston JA, Cunningham VJ, Asselin MC, Hammers A, Evans $A C$ Gunn RN. Positron emission tomography partial volume correction: estimation and algorithms. J Cereb Blood Flow Metab 2002;22:10191034.

36. Wang J, del Valle M, Goryawala M, Franquiz JM, McGoron AJ. Computer-assisted quantification of lung tumors in respiratory gated PET/CT images: phantom study. Med Biol Eng Comput 2010;48:4958 